\title{
ELECTROCHEMISTRY OF FUMING SULPHURIC ACIDS-II. CURRENT/VOLTAGE CHARACTERISTICS AT A PLATINUM ROTATING DISK ELECTRODE*
}

\author{
J. S. W. Carrozza, H. A. Garrera and A. J. Arvita \\ Instituto Superior de Investigaciones, Facultad de Química y Farmacia, \\ Universidad Nacional de La Plata, La Plata, Argentina
}

\begin{abstract}
Anodic and cathodic processes involved in the electrolysis of different oleums were studied on platinum rotating disk electrodes at 25 and $50^{\circ} \mathrm{C}$, in a range of rotation speeds from 260 to $2000 \mathrm{rpm}$.

Anodic processes do not change with the rate of stirring. The cathodic process occurring at low overvoltages comprises a limiting current linearly related to the concentration of free $\mathrm{SO}_{\mathrm{s}}$. The anodic and cathodic Tafel lines previously determined with the electrolyte at rest are confirmed. It is concluded that the cathodic process occurring at low overvoltages involves the reduction of a solvated $\mathrm{SO}_{3}$. The effective diffusion coefficient of the latter is evaluated.
\end{abstract}

REsumo-Les processus anodiques et cathodiques dans l'électrolyse de differents oléums ont eté étudiés au moyen de l'électrode à disque tournant de platine à 25 et $50^{\circ} \mathrm{C}$ en changeant la vitesse de rotation depuis 260 jusqu' à $2000 \mathrm{rpm}$.

Les processus anodiques ne changent pas avec la variation de la vitesse de rotation, tandis que dans le processus cathodique apparait à de basses surtensions un courant limite en relation linéaire avec la concentration du SO, libre. Les pentes de Tafel antérieurement détérminées avec l'electrolyte au repos ont été confirmb́es. Les conclusions montrent que le processus cathodique à de basses surtensions entraîne la réduction du SO, solvaté. Le coefficient de diffusion effectif de cette espece a été évalué.

Zusammenfassung - Man untersuchte die anodischen und kathodischen Vorgänge bei der Elektrolyse von Oleum verschiedener Konzentration an einer rotierenden Scheibenelektrode aus Platin bei 25 und $50^{\circ} \mathrm{C}$ und Drehzahlen zwichen 260 und $2000 \mathrm{UpM}$.

Die anodischen Prozesse werden durch die Drehzahl der Elektrode nicht beeinflusst. Die kathodischen Prozesse errichen bei kleiner Úberspannung einen Grenzstrom, der linear von der Konzentration an freiem $\mathrm{SO}_{a}$ abhängt. Die früher in ruhendem Elektrolyten erhaltenen Tafel-Linien konnten bestätigt werden. Es wird gefolgert, dass der bei kleiner Uberspannung ablaufende kathodische Vorgang die Reduktion eines gelösten SO,-Moleküls einschliesst. Man bestimmte den effektiven Diffusionskoeffizienten dieses Teilchens.

\section{INTRODUCTION}

IN PART I, 1 the kinetic parameters of the cathodic and anodic reactions occurring during the electrolysis of fuming sulphuric acids were determined using both bright and platinized platinum electrodes with the electrolyte at rest. Those results, however, could not be entirely assigned to the existence of activated electrochemical processes only, in the whole potential region investigated, particularly in the cathodic reaction, because of the simultaneous occurrence of a convective-diffusional process. To determine the diffusional contribution in the electrochemical reactions both the anodic and cathodic reactions were studied on a rotating platinum disk electrode, which proved particularly adequate for the purpose. ${ }^{2}$

\section{EXPERIMENTAL TECHNIQUE}

A three-compartment Pyrex-glass electrolysis cell was used. It has essentially the same features as those already described in Part $I_{,}{ }^{1}$ except for the following two details: (i) the addition of a tap adequately protected and lubricated by the fuming

- Manuscript received 29 September 1967. 
acid itself, its purpose being to properly separate the working electrode from the counter-electrode section of the cell, (ii) the use of a $0 \cdot 3-\mathrm{cm}$ diameter platinum rod (purity $99.9 \%$ ) as the working electrode, sealed into a Pyrex-glass rod. The end of the piece was polished to a mirror surface, whose total diameter was about $1 \mathrm{~cm}$. The electrode was mounted on a rotating stainless steel shaft, confining an inner electric contact between the metals. The shaft was covered with Pyrex-glass tubing, thus preventing any attack by the acid, and was finally coupled to the driving motor.

A platinized-platinum electrode was used as a reference electrode. It attained easily reproducible potentials, although the couple platinum-disk/reference-electrode behaves as an asymmetrical electrochemical system. The deviation appeared to increase as the concentration of sulphur trioxide in the oleum decreased.

The rest of the electric contacts and the mechanical holder are essentially the same as those described previously. ${ }^{3}$ The driving motor was a synchronous dynamotor fed by an electronically regulated low voltage power pack. The circuitry also comprised an automatically driven couple balance. The rotation speed was determined after calibration of the driving motor power-pack set. This was done by measuring the frequency of an ac induced current generated at a coil by a set of small magnets uniformly distributed in a Lucite disk which was firmly bound to the rotating shaft. The frequency of the induced current was composed with the signal of an audiofrequency oscillator on the oscilloscope screen. The rotation speed wascalculated from the Lissajous figures, and varied from 260 to $2000 \mathrm{rpm}$. The electrical circuitry, chemicals, solutions employed, the constant temperature device and the techniques of chemical analysis were the same as those described in Part I. Experiments were made at 25 and $50^{\circ} \mathrm{C} \pm 0.05^{\circ} \mathrm{C}$.

Each experiment was started after a stable initial pd between the working and the reference electrode was achieved. The potential was read at values corresponding to a logarithmic progression of the current intensity. The current/voltage curves were obtained by changing the potential from higher to lower values and vice versa, trying to reproduce at the end of each run the initial potential. The steady readings in both directions usually differed very little. Each steady current/voltage value was obtained after 1-2 h, the longer time being needed the lower the current intensity, as observed earlier in Part I.

The working electrode was intermittently polished between experiments, particularly after cathodic runs at voltages higher than $1.0 \mathrm{~V}$ or thereabouts had been performed. The pseudo-ohmic drop was evaluated from the instantaneous jump of the electrode potential obtained on the oscilloscope screen, switching the electrolysis current on or off and using different sweeping rates of the electronic beam as described previously.

Experiments with concentrated sulphuric acid $(97.4$ per cent were also made with the platinum rotating disk electrode, the purpose being to compare under the same experimental conditions the electrochemical behaviour of an acid with no free sulphur trioxide and containing just a small excess of water with that of the fuming sulphuric acids.

The kinematic viscosities of the different solutions were required for the interpretation of results. They were determined with a Cannon-Fenske ASTM No. 150 viscosimeter having a constant of $3.115 \times 10^{-5}$ stokes/s, and converted to dynamic viscosities by taking the oleum densities from literature. ${ }^{4}$ 


\section{RESULTS}

\section{Cathodic current/voltage curves}

Typical cathodic current/voltage curves are shown in Fig. 1. They show a clear limiting current intensity, at different speeds of rotation. Figures 1 and 2 are semilogarithmic plots of cathodic current/voltage curves. They show three clearly distinguishable regions. (i) At $\log I$ (where $I$ is the current intensity in $\mu \mathrm{A}$ ), between 1 and 2 , there is a first straight line region comprising a Tafel slope, $\left(b_{T}\right)_{i}$, of $2 \cdot 3(R T / F)$,

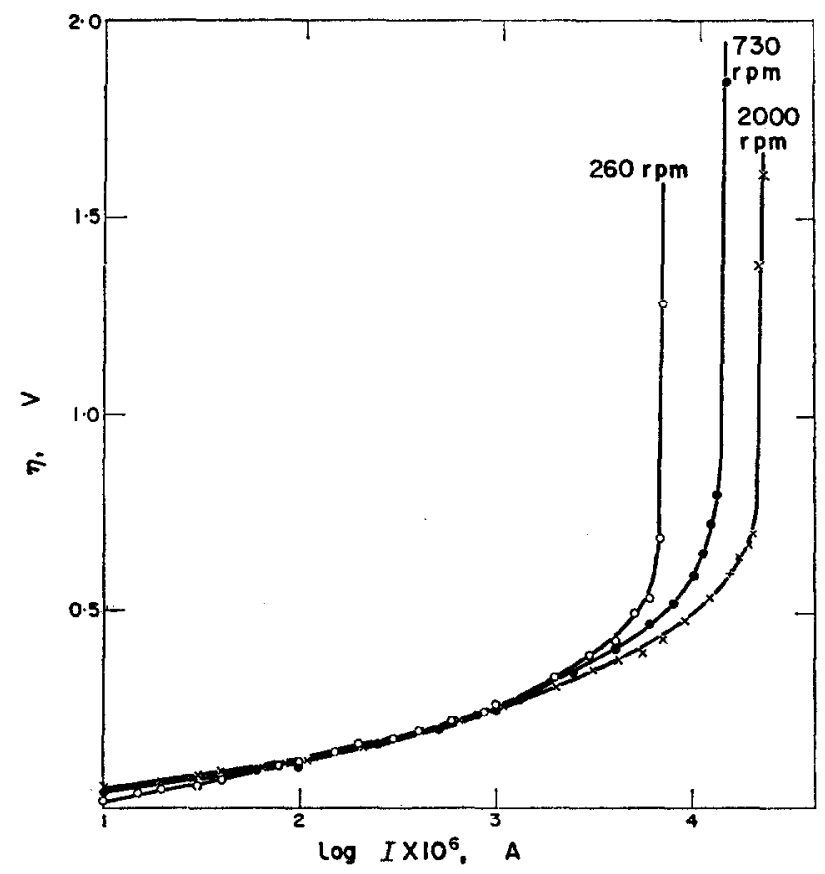

Fig. 1. Semilogarithmic plot of cathodic current/voltage curves. $\mathrm{CsO}_{2}, 27.7 \% ; \mathrm{CSO}_{2}, 0.0186 \mathrm{~N} ; 25^{\circ} \mathrm{C}$.

which extends up to about $0.3 \mathrm{~V}$. (ii) At $\log I$ between 2 and 3 thereabouts, a second straight line can be acceptably drawn. Its slope $\left(b_{T}\right)_{\mathrm{ii}}$ changes from one experiment to another but is essentially between 0.140 and $0.250 \mathrm{~V}$. No change was observed in the current/voltage curves in regions (i) and (ii) at different rates of stirring. (iii) Finally the overvoltage increases abruptly and a well defined limiting current, $I_{\mathrm{L}}$, is established. The latter changes linearly with the concentration of sulphur trioxide, at constant rotation speed, as indicated in Fig. 3. At fixed concentration, it changes linearly with the square root of the rotation speed, $\omega$, as shown in Fig. 4.

The region of the first Tafel line is mainly related to sulphur dioxide formation. Visible hydrogen formation takes place only beyond the region of the limiting current. In regions (ii) and (iii) the formation of an opaque yellowish film of sulphur was often observed. When the latter is formed, it produces a change of the electrode surface, reflected in the non-coincidence of current/voltage curves traced from the higher to the lower overvoltages and vice-versa.

Cathodic experiments performed at $50^{\circ} \mathrm{C}$ are characterized by a lower overvoltage and as a consequence, the current/voltage curves exhibit region (i) covering a more 


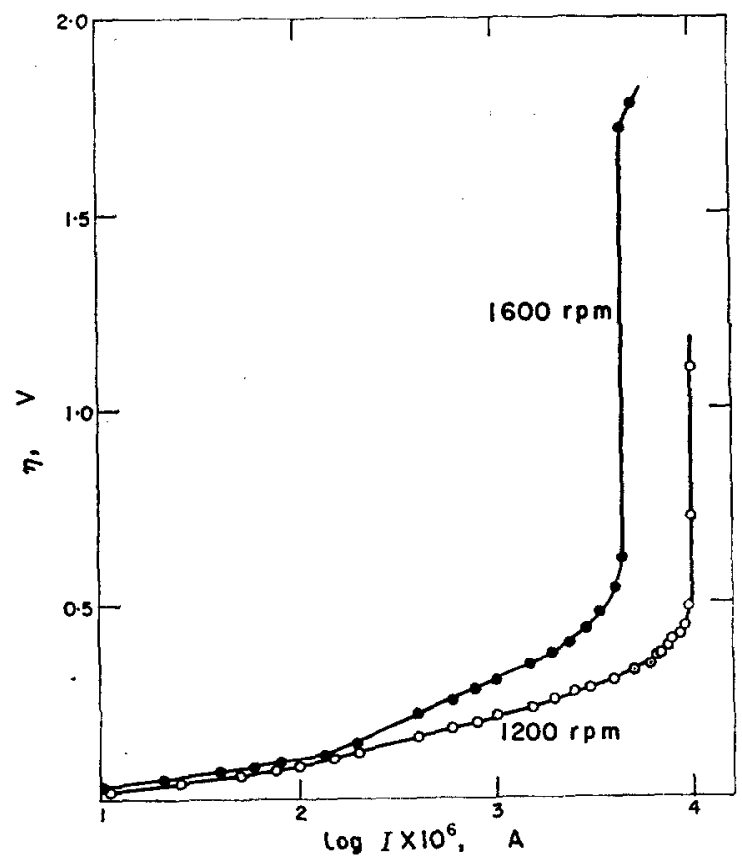

FIG. 2. Semilogarithmic plot of cathodic current/voltage curves.

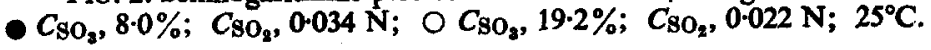

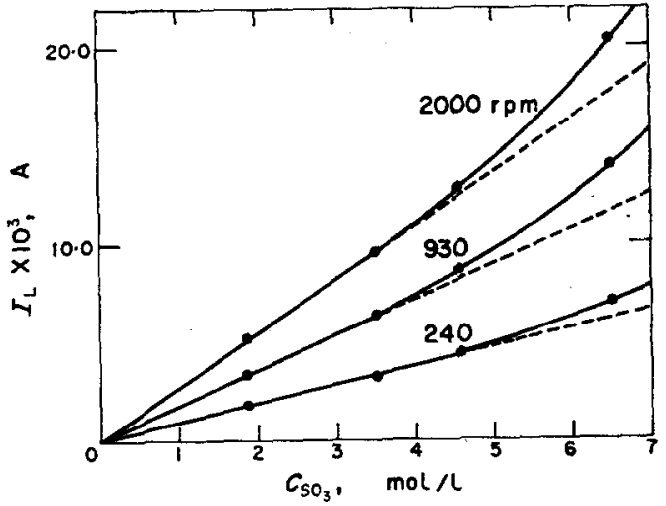

FIG. 3. Linear relationship between cathodic limiting current and concentration of free sulphur trioxide in the oleums; $25^{\circ} \mathrm{C}$. 


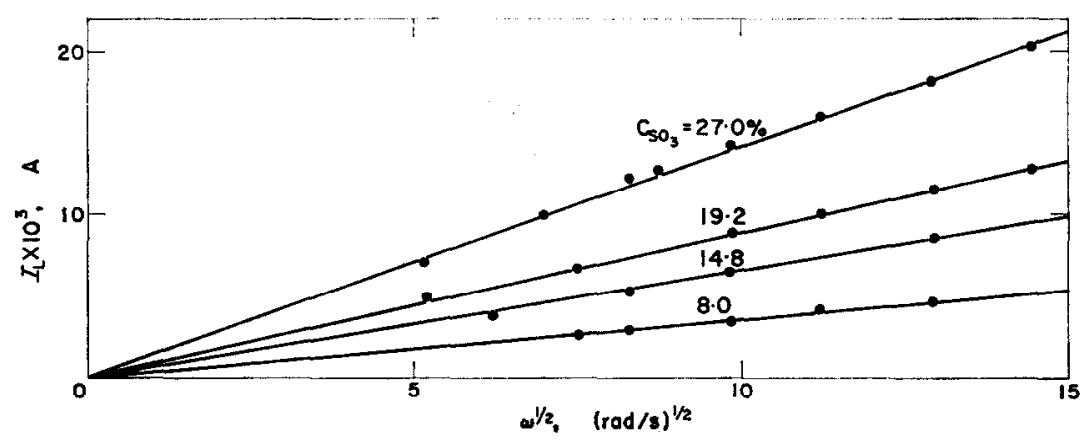

Fig. 4. Plot of $\left(I_{L}\right)_{e} v s \omega^{1 / 2}$.

extended current range. Region (ii) has practically disappeared at this temperature, as observed in Fig. 5.

Data derived from cathodic current/voltage curves are assembled in Table 1. The extrapolation of the first Tafel line was done both at a null rest potential $\left(E_{\mathrm{r}}=0\right)$, which would be the case if the working-electrode/reference-electrode couple behaved as a symmetrical system, and at null overvoltage $(\eta=0)$. The rest potential appeared

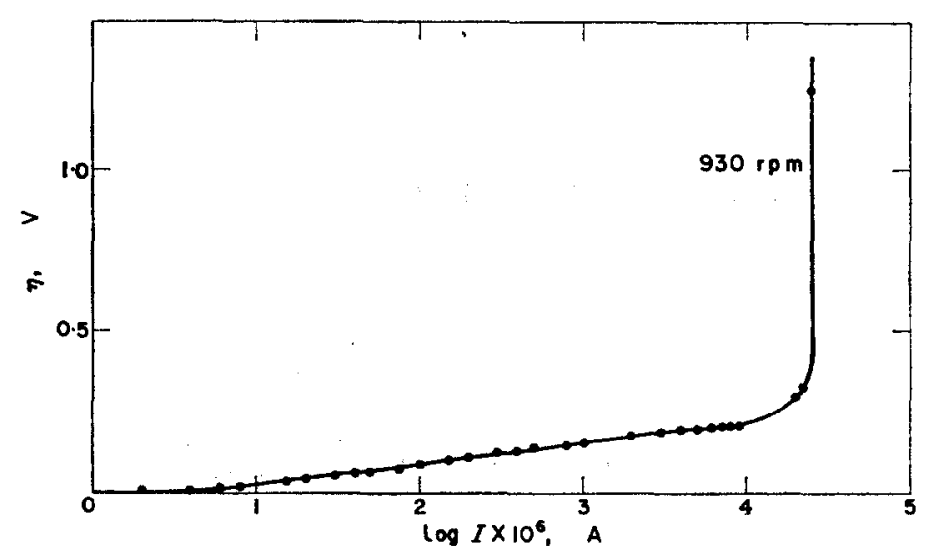

FIG. 5. Semilogarithmic plot of cathodic current/voltage curve. $\mathrm{C}_{\mathrm{SO}_{2}}, 27.7 \% ; \mathrm{C}_{\mathrm{SO}_{2}}, 0.0186 \mathrm{~N} ; 50^{\circ} \mathrm{C}$.

strongly dependent on the solution composition, although for any particular one, very reproducible results were obtained. The logarithm of the apparent exchange cds, $\left(i_{0}\right)_{\mathrm{k}=0}$ and $\left(i_{0}\right)_{\eta=0}$, are indicated in Table 1 . While the former changes appreciably with the different solutions, the latter shows a relatively constant value at the fixed temperature.

\section{Anodic current/voltage curves}

Figures 6 and 7 show typical anodic current/voltage curves, obtained with the fuming sulphuric acids. They are characterized by an initial steady overvoltage increase with current and later by the appearance of a limiting cd of a value between $10^{-6}$ and $10^{-4} \mathrm{~A} / \mathrm{cm}^{2}$, as estimated at the inflexion point of the curve.

The initial region of the anodic current/voltage curves, including the limiting 


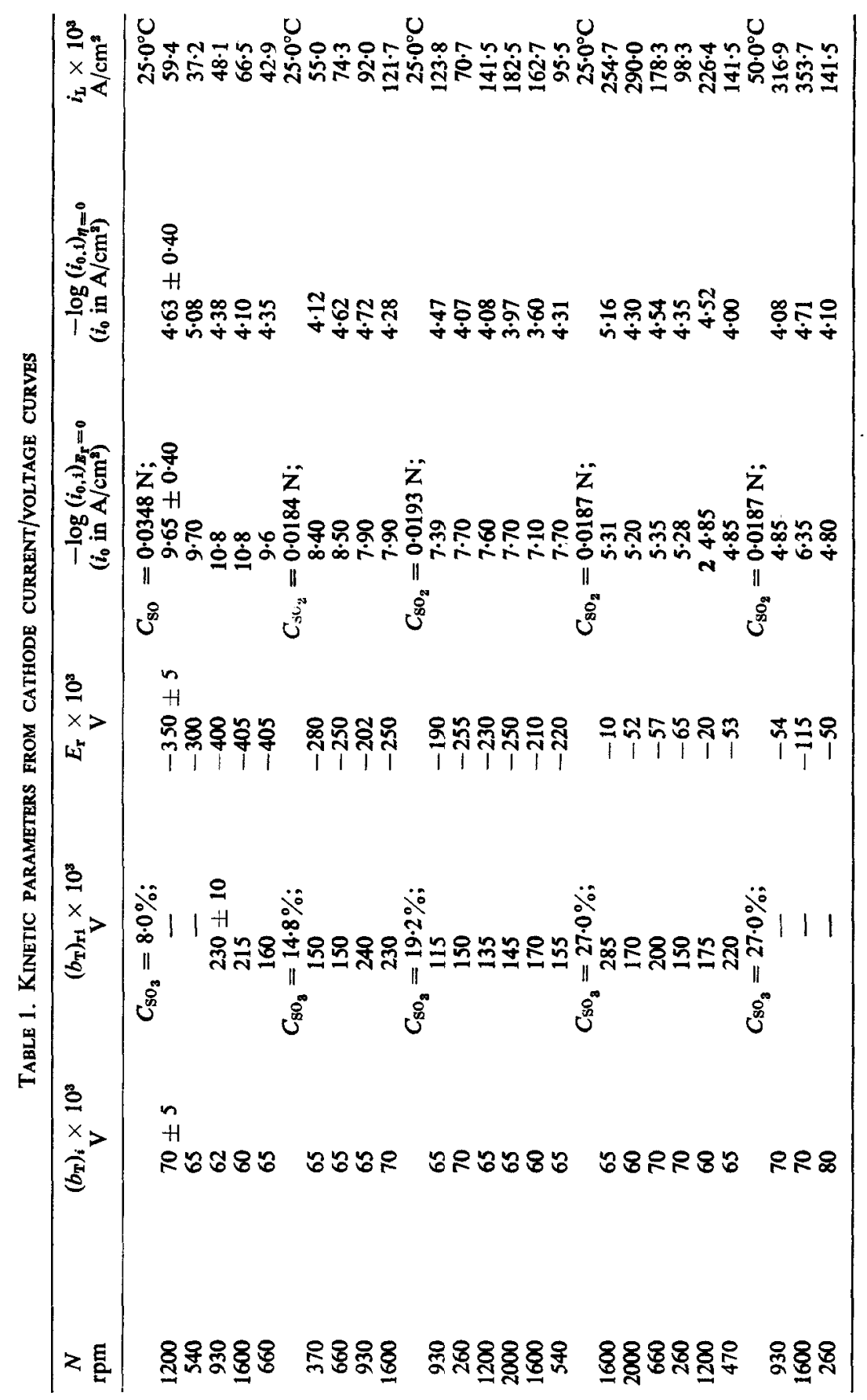




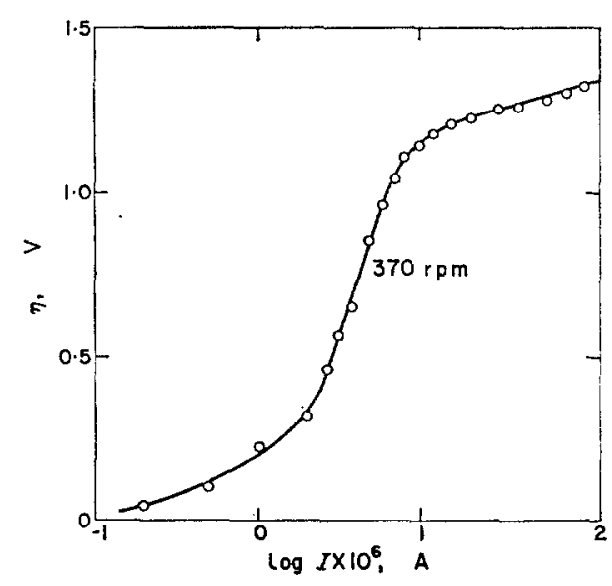

FrG. 6. Semilogarithmic plot of anodic current/voltage curve.

$C_{\mathrm{SO}_{3}}=27.7 \% ; C_{\mathrm{SO}_{2}}=0.0186 \mathrm{~N} ; 25^{\circ} \mathrm{C}$.

cd, is rather irreproducible and depends on whether the curve is determined by increasing or by decreasing the current. In the present case this sort of hysteresis means that the returning curve exhibits a larger overvoltage than the one obtained by increasing the anodic voltage. Sometimes the returning curve obtained from higher overvoltages did not follow the previously observed limiting cd, and a marked change

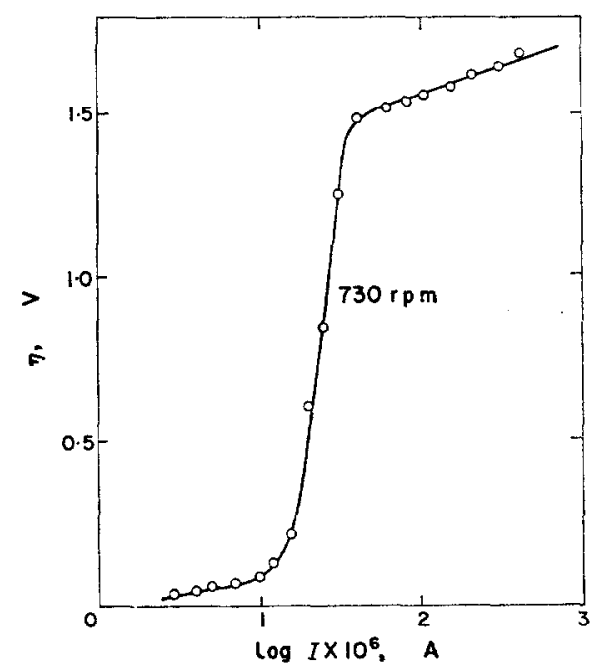

FIG. 7. Semilogarithmic plot of anodic current/voltage curve.

$C_{\mathrm{SO}_{3}}=27.7 \% ; C_{\mathrm{SO}_{2}}=0.0186 \mathrm{~N} ; 25^{\circ} \mathrm{C}$.

in the rest potential was also observed. It should be stressed that the time required to obtain a steady set of readings in this part of the current/voltage curve was on the average about $1 \mathrm{~h}$.

Neither the rotation speed of the anode, nor sulphur dioxide nor sulphur trioxide concentrations, affected in an appreciable way the limiting cd found in the anodic experiments. 


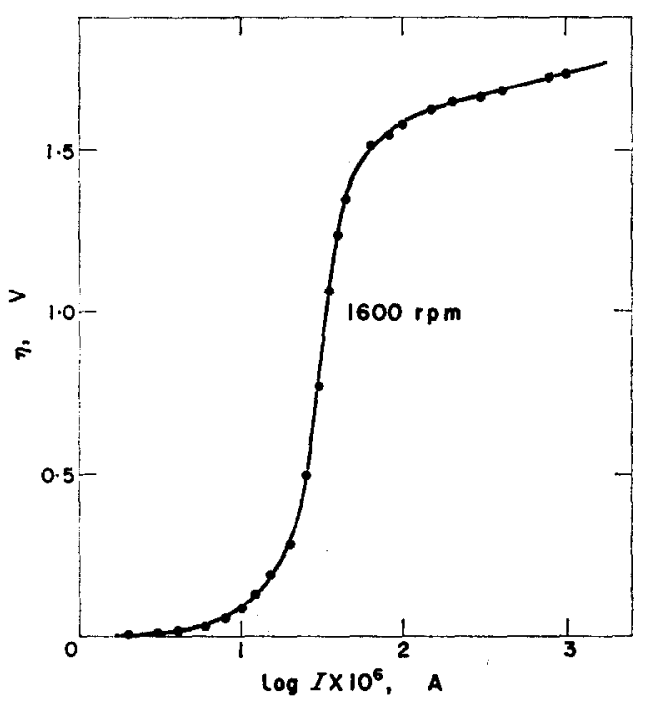

Fig. 8. Semilogarithmic plot of anodic current/voltage curve.

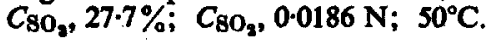

These effects suggest that besides the probable electrochemical oxidation of sulphur dioxide ${ }^{5}$ a modification of the electrode surface occurs during anodization.

At voltages larger than $1.2 \mathrm{~V}$, a well defined Tafel line appears, related to both the oxygen and permonosulphuric acid formation. It has a slope close to $2 \cdot 3(2 R T / F)$ independent of the rotation speed of the working electrode. Current/voltage curves traced in either direction were coincident in this region. Stable readings were obtained in a shorter time than at lower voltages.

In only a few experiments this Tafel slope became appreciable greater than $2 \cdot 3(2 R T / F)$ and that occurred when an anodic voltage larger than $1.8 \mathrm{~V}$ was attained. Usually then the appearance of yellowish products was noted, probably caused by the oxidation of the electrode material. ${ }^{6}$

Anodic experiments at $50^{\circ} \mathrm{C}$ show the same features already described for $25^{\circ} \mathrm{C}$, (Fig. 8). Data obtained from the anodic runs are assembled in Table 2. The apparent anodic exchange cd, $\left(i_{0}\right)_{a}$, was evaluated by extrapolating the anodic Tafel line of slope $\left(b_{T}\right)_{\mathrm{a}}$ to null rest potential $\left(E_{\mathrm{r}}=0\right)$ and null overvoltage $(\eta=0)$.

TABLE 2. KINETIC PARAMETERS FRom aNODIC CURRENT/VOLTAGE CURVES

\begin{tabular}{|c|c|c|c|c|c|c|c|}
\hline$\left(\%\right.$ free $\left.\mathrm{SO}_{3}\right)$ & $\mathrm{N}_{\mathrm{N}}^{\mathrm{CsO}}$ & $\underset{{ }^{\circ} \mathrm{C}}{\text { Temp. }}$ & $\underset{\mathrm{rpm}}{N}$ & $b_{T} \times 10^{s}$ & $E_{\mathrm{r}} \times 10^{9}$ & $-\log \left(i_{0,2}\right)_{z_{\mathbf{r}}=0}$ & $-\log \left(i_{0, \mathrm{a}}\right)_{\eta=0}$ \\
\hline $\begin{array}{r}8 \cdot 0 \\
21 \cdot 0 \\
27 \cdot 0 \\
27 \cdot 0 \\
27 \cdot 0 \\
27 \cdot 0 \\
27 \cdot 0 \\
27 \cdot 0\end{array}$ & $\begin{array}{l}0.035 \\
0.215 \\
0.0187 \\
0.0187 \\
0.0187 \\
0.0187 \\
0.0187 \\
0.0187\end{array}$ & $\begin{array}{l}25 \cdot 0 \\
25 \cdot 0 \\
25 \cdot 0 \\
25 \cdot 0 \\
25 \cdot 0 \\
25 \cdot 0 \\
50 \cdot 0 \\
50 \cdot 0\end{array}$ & $\begin{array}{r}1200 \\
660 \\
260 \\
930 \\
1600 \\
1200 \\
930 \\
1600\end{array}$ & $\begin{array}{l}140 \pm 10 \\
145 \\
125 \\
120 \\
125 \\
130 \\
130 \\
125\end{array}$ & $\begin{array}{l}-390 \pm 10 \\
+290 \\
-130 \\
-98 \\
-12 \\
-24 \\
-78 \\
-100\end{array}$ & $\begin{array}{l}14 \cdot 7 \pm 0.4 \\
16 \cdot 0 \\
13 \cdot 2 \\
13 \cdot 3 \\
13 \cdot 8 \\
13 \cdot 0 \\
14 \cdot 2 \\
14 \cdot 8\end{array}$ & $\begin{array}{l}17 \cdot 5 \pm 0.4 \\
14 \cdot 0 \\
14 \cdot 2 \\
14 \cdot 1 \\
13 \cdot 9 \\
13 \cdot 1 \\
14 \cdot 8 \\
15 \cdot 6\end{array}$ \\
\hline
\end{tabular}




\section{Results with concentrated sulphuric acid}

A series of cathodic and anodic experiments with $97.4 \%$ sulphuric acid were performed to obtain additional kinetic information in Part I. These experiments were performed at $25^{\circ} \mathrm{C}$ only.

Figure 9 shows a cathodic current/voltage semilogarithmic plot. Data fit a Tafel line with a slope very close to $2 \cdot 3(2 R T / F)$, starting at about $0.5 \mathrm{~V}$. The apparent

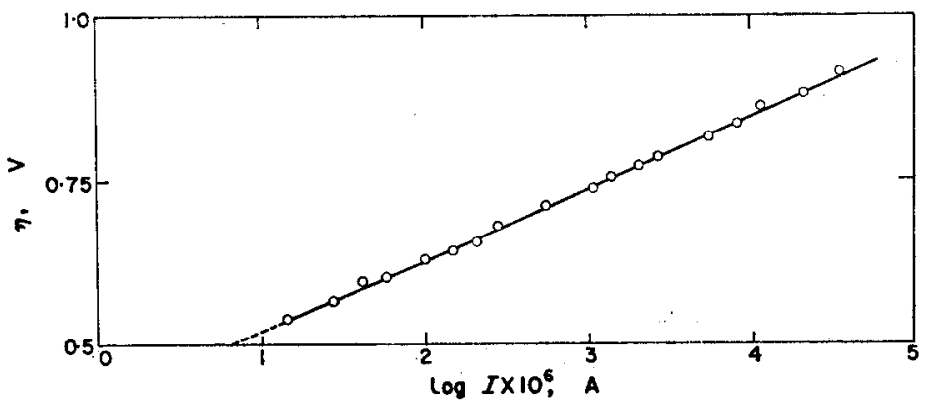

FIG. 9. Semilogarithmic plot of cathodic current/voltage curve obtained with concentrated sulphuric acid.

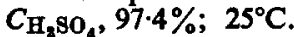

exchange cds obtained either at the rest potential or at $\eta=0$ are shown in Table 3. These kinetic parameters agree with those earlier obtained for the hydrogen discharge reaction on platinum electrodes. ${ }^{7}$ They are unaffected by the rotation speed and are very reproducible. There was also some hysteresis effect here, particularly in the region of high cds, and at the end of each run the working electrode had lost its initial brightness.

TABLE 3. KINETIC PARAMETERS FROM CURRENT/VOLTAGE CURVES WTTH CONCENTRATED SULPHURIC ACID (97.4 PER CENT). $25 \cdot 0^{\circ} \mathrm{C}$

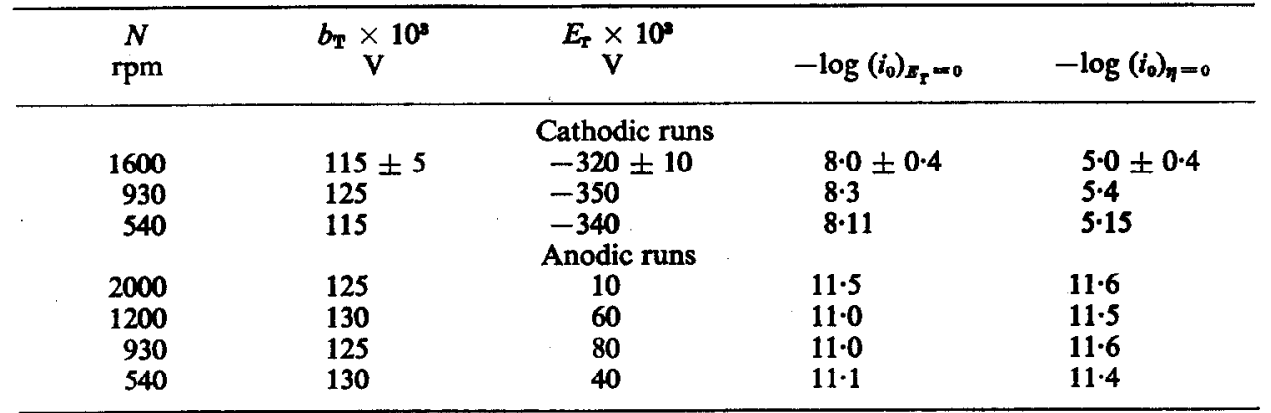

Figure 10 presents an anodic run. Initially there is a rapid increase of potential until a voltage of 1.1 to $1.2 \mathrm{~V}$ is reached. Afterwards a Tafel line appears having a slope of $2 \cdot 3(2 R T / F)$. Its extrapolation either to $E_{\mathrm{r}}=0$ or to $\eta=0$ yields reasonably coincident apparent exchange cds as shown in Table 3. At voltages higher than 1.3, the anodic current/voltage curve shows a steady increase of the Tafel slope as already described for the oleums. In this case there was also a modification of the rest potential after electrolysis, as compared to the initial value; the difference was slightly smaller than for the fuming acids. 


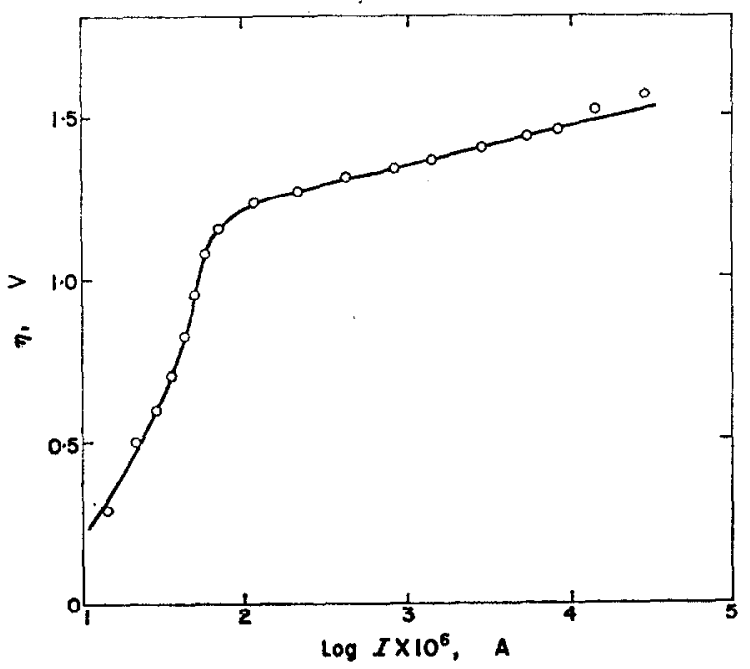

FIG. 10. Semilogarithmic plot of anodic current/voltage curve obtained with concentrated sulphuric acid.

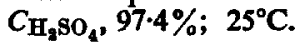

\section{Viscosity and density measurements}

Results for viscosity, $v$, and density, $\rho$, of oleums are indicated in Table 4. These data are required for the evaluation and interpretation of the cathodic diffusion process.

TABLE 4

\begin{tabular}{|c|c|c|c|c|c|c|}
\hline$\left(\begin{array}{c}\mathrm{CsO}_{3} \\
\left(\% \text { free } \mathrm{SO}_{8}\right)\end{array}\right.$ & $\mathrm{Cso}_{\mathbf{M}}$ & $\begin{array}{l}\rho_{25 \circ C} \\
\mathrm{~g} / \mathrm{cm}^{2}\end{array}$ & $\begin{array}{c}v_{255^{\circ} \mathrm{c}} \times 10^{2} \\
\mathrm{~cm}^{2} / \mathrm{s}\end{array}$ & $\begin{array}{l}D_{i} \times 10^{\mathrm{s}} \\
\mathrm{cm}^{2} / \mathrm{s}\end{array}$ & $\begin{array}{c}\left(D_{i} \eta / T\right) \times 10^{10}{ }^{10} \\
\mathrm{~cm}^{2} . \text { poise/s }{ }^{\circ} \mathrm{K}\end{array}$ & $\begin{array}{c}r_{i} \times 10^{8} \\
\mathrm{~cm}\end{array}$ \\
\hline $\begin{array}{r}8 \cdot 0 \\
14 \cdot 8 \\
19 \cdot 2 \\
27 \cdot 0\end{array}$ & $\begin{array}{l}1.86 \\
3.49 \\
4.56 \\
6.50\end{array}$ & $\begin{array}{l}1.864 \\
1.888 \\
1.902 \\
1.927\end{array}$ & $\begin{array}{l}13 \cdot 12 \\
13 \cdot 49 \\
13 \cdot 92 \\
15 \cdot 33\end{array}$ & $\begin{array}{c}6 \cdot 57 \\
6 \cdot 25 \\
(6 \cdot 76) \\
(8 \cdot 27)\end{array}$ & $\begin{array}{c}0.538 \\
0.533 \\
(0 \cdot 600) \\
(0.819)\end{array}$ & $\begin{array}{r}13.6 \\
13.7 \\
(12.2) \\
(8.9)\end{array}$ \\
\hline
\end{tabular}

\section{DISCUSSION}

Recent spectroscopic investigations of the system $\mathrm{H}_{2} \mathrm{O}-\mathrm{SO}_{3}$ have shown that for oleums in the range of free sulphur trioxide concentrations between 0 and 30 per cent, sulphur trioxide is mainly present as disulphuric acid. ${ }^{8}$ The latter participates in the equilibrium

$$
\mathrm{H}_{2} \mathrm{SO}_{4}+\mathrm{H}_{2} \mathrm{~S}_{2} \mathrm{O}_{7} \rightleftharpoons \mathrm{H}_{3} \mathrm{SO}_{4}^{+}+\mathrm{HS}_{2} \mathrm{O}_{7}^{-} \text {. }
$$

The dissociation constant, at $25^{\circ} \mathrm{C}$, involved in reaction (1) is $1.4 \times 10^{-2,9}$ yielding consequently a relatively low degree of ionization of disulphuric acid. Therefore, as compared to the rest of ionic species present in the diluted oleums, the contribution of disulphuric acid to ionic migration can be assumed to be negligible. This assumption facilitates a rather simple interpretation of the convection-diffusion process observed in the cathodic reaction at low concentrations of free sulphur trioxide, and justifies the application to that process of any of the rate equations derived for the rotating disk electrode. According to Levich's solution ${ }^{10}$ for that electrode, the 
limiting $\mathrm{cd}, i_{\mathrm{L}}$, for the electrode reaction under convective-diffusion control is

$$
i_{\mathrm{L}}=0.62 z F D^{2 / 3^{-1}}{ }^{-1 / 6} C \omega^{1 / 2},
$$

where $z$ is the number of electrons entering the whole reaction, $F$ the Faraday constant, $C$ the concentration of the reacting species in the bulk, $D$ its effective diffusion coefficient and $\omega$ the speed of rotation of the disk electrode. The dependences so predicted of $i_{\mathrm{L}}$ on $\omega$ and on $C$ agree in principle with the experimental results. From the slope of the $i_{\mathrm{L}} / \omega^{1 / 2}$ plot, the experimental diffusion coefficient of the diffusing species is

$$
D=\left[\frac{S v^{1 / 6}}{0.62 z F C}\right]^{3 / 2},
$$

where $S$ is the slope of the $i_{\mathrm{L}} / \omega^{1 / 2}$ plot.

The total cathodic reaction related to convective-diffusion process can be written

$$
\left(\mathrm{SO}_{3}\right)_{\mathrm{FSA}}+2\left(\mathrm{H}^{+}\right)_{\mathrm{FSA}}+2 \mathrm{e} \rightleftarrows\left(\mathrm{H}_{2} \mathrm{O}\right)_{\mathrm{FSA}}+\left(\mathrm{SO}_{2}\right)_{\mathrm{FSA}} \text {, }
$$

where the species are considered as solvated entities in the fuming sulphuric acid. Values of $D$ calculated with (3) and taking $z=2$, and $C$ equal to the total disulphuric acid concentration, are assembled in Table 4.

Since the viscosities were also determined and we are dealing with a newtonian fluid, the Einstein-Stokes ratio can be estimated,

$$
\frac{D \eta}{T}=\frac{k}{6 \pi r_{1}},
$$

where $r_{1}$ is the apparent average radius of the solvodynamic unit, $\eta$ the dynamic viscosity and $k$ Boltzmann's constant. The Einstein-Stokes ratio as shown in Table 4 is satisfactorily constant, at lower concentrations of free sulphur trioxide. The values of $r_{i}$, calculated with (5), are assembled in Table 4.

The Einstein-Stokes radii can be related to the actual size of the moving species when relatively large entities participate in the transport phenomena, since in such a case the system can be dealt with as a continuum. If such a condition is approached, the apparent average radius suggests that the actual size of the diffusing species, at least in the more diluted oleums, is larger than that of either the sulphur trioxide or the disulphuric acid molecule. However, due to the relatively complex structures of oleums, it is not possible to draw further conclusions about the solvation state of the diffusing entity. But independently of any possible solvated structure and its dependence on the concentration of sulphur trioxide in the oleum, it can be definitely concluded that, at least in the more diluted oleums, solvated sulphur trioxide (disulphuric acid) participates in the cathodic reaction at low overvoltages.

The rest of the kinetic parameters, as far as the Tafel slopes are concerned, are coincident with those earlier deduced from the study with the electrolyte at rest. The situation appears somewhat different in the region of the cathodic current/voltage curve preceding the limiting cd, where a rather large slope is involved, but this is not surprising because apart from the proximity of the limiting cd region at these overvoltages the occasional sulphur-film formation should also be taken into account, thus adding a further complication. Significant contributions of activated processes are involved in the anodic and cathodic current/voltage curves, as earlier reported, although they are at present difficult to analyse because of the simultaneous occurrence of several reactions, particularly at high overvoltages. 
Finally, the activity of the working electrode seems very poor, as far as the rest potentials are concerned. This fact makes an appreciable difference in the $i_{0}$ values obtained at $E=0$ and $\eta=0$. Consequently, the differences in the $i_{0}$ values between experiments previously reported ${ }^{1}$ and the present results, reflects the different activity of the working electrodes used.

Acknowledgement-This work was in part supported with funds of the Consejo Nacional de Investigaciones Cientficas y Ténicas of Argentina. H. A. Garrera is grateful for the fellowship granted by the University of Cuyo.

\section{REFERENCES}

1. H. A. Garrera, J. S. W. Carrozza and A. J. Arvia, Electrochim. Acta 13, 771 (1968).

2. A. C. RIDDIFORD, in Advances in Electrochemistry and Electrochemical Engineering, ed. P. Delahay and C. W. Tobias, Vol. 4, p. 47. Interscience, New York (1966).

3. J. C. BAZÁN and A. J. ARvíA, Electrochim. Acta 10, 1025 (1965).

4. P. Pascal, Nouneau Traité de Chimie Minérale, T.XIII, (II), p. 1330. Masson, Paris (1961).

5. A. M. Susho, Trudy Dal'nevost Tekh. Inst. Ryb. Prom. Khoz. 3, 121 (1963); C.A. 66, 81857 (1967).

6. M. Pounanix, Atlas of Electrochemical Equilibria in Aqueous Solutions, p. 378. Pergamon, Oxford (1966).

7. K. J. VETTER, Elektrochemische Kinétik, p. 430. Springer, Berlin (1961).

8. K. STOPPERKA, Z. anorg. allg. Chem. 345, 264 (1966).

9. R. J. GrLlaspie and E. A. RoBrnson, in Advances in Inorganic Chemistry and Radiochemistry, Vol. 1, p. 389. Academic Press, New York (1959).

10. B. LeviCH, Physiochemical Hydrodynamics, p. 69. Prentice-Hall, Englewood Cliffs, N.J. (1962). 